\title{
Arrhythmias and intracardiac conduction after the arterial switch operation
}

Intraatrial baffling procedures such as the Mustard or Senning repair of transposition of the great arteries have been associated with a high incidence of cardiac arrhythmias. These abnormalities are thought to arise from trauma to the sinus node and atrial muscle during the procedure. In the arterial switch operation, there is little intraatrial manipulation other than the repair of the atrial septal defect. In theory, rhythm disturbances after the arterial switch operation should be less prevalent. From January 1, 1983, to December 31, 1990, 390 patients (230 with intact ventricular septum and 160 with a coexisting ventricular septal defect) underwent an arterial switch operation. Electrocardiograms and 24-hour Holter monitor studies were obtained in the 364 survivors at hospital discharge and during follow-up. Limited intracardiac electrophysiologic studies were performed 6 to 12 months after the operation. Results: Atrioventricular node function was preserved in most patients; seven patients $(2 \%)$ had first-degree, two $(0.7 \%)$ second-degree, and five $(1.7 \%)$ had complete atrioventricular block (all with coexisting ventricular septal defect). All five patients with complete heart block received a permanent pacemaker. In those patients not having a permanent pacemaker, sinus rhythm was present in $96 \%$ on the surface electrocardiogram and $99 \%$ during 24-hour Holter monitor studies ( 1 month to 8.5 years, mean 2.1 years after the operation). Intracardiac electrophysiologic studies $(n=158)$ demonstrated normal corrected sinus node recovery times and $\mathrm{AH}$ intervals in $97 \%$ of patients. Atrial ectopy was present in 152 of $172(81 \%)$ patients, with the majority $(64 \%)$ of patients having only occasional premature beats without repetitive forms. Ventricular ectopy was a frequent finding during 24-hour monitoring. At hospital discharge $70 \%$ had ventricular ectopy; these values fell to $57 \%$ (in patients with intact ventricular septum) and 30\% (in patients with a coexisting ventricular septal defect) at follow-up. In the early postoperative period, there were 25 episodes of supraventricular tachycardia (14 of which required therapy), 6 episodes of junctional ectopic tachycardia, and 9 episodes of ventricular tachycardia. The incidence of supraventricular tachycardia had fallen to $5 \%$ at follow-up, with no atrial flutter or fibrillation noted. Three patients had ventricular tachycardia on follow-up Holter studies. In summary, our results confirm the theoretical advantages of anatomic correction over atrial level correction of transposition of the great arteries with respect to preservation of sinus node function and low incidence of clinically significant tachyarrhythmias. (J THORAC CARDrOvaSC SURG 1995;109: 303-10)

Larry A. Rhodes, MD, ${ }^{*}$ Gil Wernovsky, MD, John F. Keane, MD, John E. Mayer, Jr., MD, Allison Shuren, RN, MSN, PNP, Christine Dindy, CCT, Steven D. Colan, MD, and Edward P. Walsh, MD, Boston, Mass.

From the Departments of Cardiology and Cardiac Surgery, Children's Hospital, and the Departments of Pediatrics and Surgery, Harvard Medical School, Boston, Mass.

Supported in part by grant HL 41786 from the National Heart, Lung, and Blood Institute, National Institutes of Health, Bethesda, Md.

Received for publication April 1, 1994.

Accepted for publication August 15, 1994.
Address for reprints: Gil Wernovsky, MD, Children's Hospital of Philadelphia, 34th St. and Civic Center Blvd., Philadelphia, PA 19104.

*Current address: Department of Pediatric Cardiology, West Virginia University School of Medicine, Morgantown, WV 26506.

Copyright (C) 1995 by Mosby-Year Book, Inc.

$0022-5223 / 95 \$ 3.00+0 \quad \mathbf{1 2 / 1 / 5 9 9 5 3}$ 
The use of an intraatrial baffling procedure such as the Mustard ${ }^{1}$ or Senning ${ }^{2}$ repairs for transposition of the great arteries (TGA) has been associated with a high incidence of cardiac rhythm abnormalities. ${ }^{3-9}$ Sinus bradycardia, complicated by recurrent atrial flutter, is the most common management issue in this population and may contribute to late sudden death. These rhythm disturbances are thought to arise from trauma to the sinus node and atrial muscle from the extensive intraatrial suture lines required in the baffling procedure. ${ }^{10}$

During the arterial switch operation there is little intraatrial manipulation other than the repair of the atrial septal defect (either congenital or caused by balloon atrial septostomy). One of the major theoretical advantages of anatomic correction is that the limited atrial procedure should result in a significantly improved rhythm status of the survivors. The purpose of this report is to review our experience in patients that have undergone an arterial switch operation for treatment of TGA (with intact ventricular septum [IVS] and ventricular septal defect [VSD]), with attention to midterm cardiac rhythm status.

\section{Methods}

Our follow-up protocol has been previously reported. ${ }^{11}$ Each patient had at least one electrocardiogram (ECG) before the operation and before discharge. Follow-up ECGs were suggested at 1,6 , and 12 months after the operation and then annually. The available ECGs were retrospectively reviewed for rhythm, rate, conduction intervals, voltages, and ST segment and T-wave morphology. Age-corrected criteria ${ }^{12}$ were used for interpretation.

Twenty-four-hour ambulatory ECG (Holter) monitor studies were obtained at discharge and were suggested at 6 to 12 months after discharge and then yearly. The discharge and last available recordings were reviewed for rhythm, rate, atrial ectopy, and ventricular ectopy. The frequency of atrial and ventricular arrhythmias was recorded and defined as shown in Table I. During the initial hospitalization, episodes of clinically apparent tachyarrhythmias were recorded.

A limited intracardiac electrophysiologic study was performed during postoperative catheterization at 6 to 12 months of age. ${ }^{11}$ At this study, sinus node recovery times were measured and corrected to the sinus cycle length. The bundle of His was localized and AH (atrium to His bundle) as well as HV (His bundle to ventricle) intervals were recorded. Right ventricular apex activation times were also determined. These results were compared with published standards. ${ }^{13}$ Group values are expressed as the mean \pm standard deviation.

The electrophysiologic results in the first 49 survivors with TGA/IVS ${ }^{11}$ and the first 62 patients with TGA/ VSD,${ }^{14}$ which have been previously reported, are included in this study. Most of the patients in this report are
Table I. Definitions of frequency of arrhythmia

\begin{tabular}{ll}
\hline Atrial arrhythmias & \\
Occasional APBs & $<15 / \mathrm{hr}$ \\
Frequent APBs & $>15 / \mathrm{hr}$ \\
SVT (nonsustained) & $<10$ beats' duration \\
SVT (sustained) & $>10$ beats' duration \\
Ventricular arrhythmias & \\
Occasional & Uniform VPBs with peak hourly \\
& count $<30$ \\
Frequent & Uniform VPBs with peak hourly \\
& count $>30$ \\
Multiform & 2 or more morphologies regardless of \\
& frequency \\
Couplets & 2 consecutive ventricular ectopic \\
& beats \\
VT (nonsustained) & 3 to 30 consecutive ventricular ec- \\
& topic beats \\
VT (sustained) & $>30$ consecutive ventricular ectopic \\
& beats
\end{tabular}

$A P B$, Atrial premature beat; $S V T$, supraventricular tachycardia; $V P B$, ventricular premature beat; $V T$, ventricular tachycardia.

followed up in other institutions, which in part explains the variability in follow-up intervals and protocol compliance. Cross-sectional follow-up was obtained by contacting the primary cardiologists in June 1992 for follow-up information. Overall results and factors related to mortality after the arterial switch operation are reported elsewhere. ${ }^{15}$

\section{Results}

Patient population. Between January 1, 1983, and December 31, 1990, 390 patients underwent an arterial switch operation at Children's Hospital, Boston, with 364 (93.3\%) survivors. TGA/IVS was present in 230, and the other 160 had a coexisting VSD. The mean age at operation was $30 \pm 92$ days (range 1 day to 2.8 years, median 6 days) in those with TGA/IVS and $6 \pm 13$ months ( 2 days to 7.8 years, median 2 months) in those with TGA/VSD. Immediately after the operation (while the patients were in the cardiac intensive care unit), there were 25 episodes of supraventricular tachycardia, of which 14 necessitated therapy (either medical or overdrive atrial pacing). Only 3 of these 25 episodes were due to atrial flutter. In addition, 6 patients had hemodynamically significant junctional ectopic tachycardia and 9 had ventricular tachycardia, all of which were treated.

No patient had symptomatic arrhythmia or syncope during follow-up. At the time of the follow-up studies, 2 patients (both with TGA/VSD) were receiving a $\beta$-adrenergic blocker. No other patient was receiving antiarrhythmic medications (other than digoxin). 
Table II. Surface ECG

\begin{tabular}{|c|c|c|c|c|}
\hline & \multicolumn{2}{|c|}{$T G A / I V S$} & \multicolumn{2}{|c|}{$T G A / V S D$} \\
\hline & $\begin{array}{l}\text { Postop. } \\
(n=199)\end{array}$ & $\begin{array}{l}\text { Follow-up } \\
(n=147)\end{array}$ & $\begin{array}{c}\text { Postop. } \\
(n=149)\end{array}$ & $\begin{array}{l}\text { Follow-up } \\
(n=147)\end{array}$ \\
\hline Sinus rhythm & $195(98 \%)$ & $143(97 \%)$ & $139(93 \%)$ & $138(94 \%)$ \\
\hline \multicolumn{5}{|l|}{ Rate (beats/min) } \\
\hline Mean & 141 & 110 & 131 & 118 \\
\hline Range & $100-205$ & $60-80$ & $75-195$ & $55-190$ \\
\hline \multicolumn{5}{|l|}{ PR interval (sec) } \\
\hline Mean & 0.11 & 0.12 & 0.12 & 0.12 \\
\hline Range & $0.07-0.17$ & $0.08-0.21$ & $0.08-0.28$ & $0.08-0.24$ \\
\hline \multicolumn{5}{|l|}{ QRS duration (sec) } \\
\hline Mean & 0.06 & 0.07 & 0.09 & 0.09 \\
\hline Range & $0.04-0.13$ & $0.04-0.12$ & $0.04-0.18$ & $0.04-0.18$ \\
\hline First-degree AV block & $5(2.5 \%)$ & $3(2 \%)$ & $3(1.3 \%)$ & $4(3 \%)$ \\
\hline Second-degree AV block & $1(0.5 \%)$ & 0 & 0 & $2(1 \%)$ \\
\hline Third-degree AV block & 0 & 0 & $6(4 \%)$ & $5(3 \%)$ \\
\hline $\mathrm{RSR}^{\prime}$ & $54(27 \%)$ & $45(31 \%)$ & $5(3.4 \%)$ & $29(20 \%)$ \\
\hline CRBBB & $9(5 \%)$ & $5(3 \%)$ & $66(44 \%)$ & $75(51 \%)$ \\
\hline Bifascicular block & $1(0.5 \%)$ & $1(0.6 \%)$ & $10(6.7 \%)$ & $12(8.2 \%)$ \\
\hline RAE & $23(12 \%)$ & $3(2 \%)$ & $24(16 \%)$ & $14(10 \%)$ \\
\hline LAE & $7(3.5 \%)$ & $1(0.6 \%)$ & $13(9 \%)$ & $7(5 \%)$ \\
\hline RVH & $74(37 \%)$ & $25(17 \%)$ & $36(24 \%)$ & $31(21 \%)$ \\
\hline LVH & $5(2.5 \%)$ & $12(8 \%)$ & $7(5 \%)$ & $6(4 \%)$ \\
\hline Ischemia & $12(6 \%)$ & $2(1 \%)$ & $4(3 \%)$ & $3(4 \%)$ \\
\hline NSSTWC & $58(29 \%)$ & $20(12 \%)$ & $14(9 \%)$ & $16(11 \%)$ \\
\hline
\end{tabular}

$E C G$, Electrocardiography; $T G A$, transposition of the great arteries; $I V S$, intact ventricular septum; VSD, ventricular septal defect; postop., obtained at hospital discharge; $A V$, atrioventricular; $C R B B B$, complete right bundle branch block; $R A E$, right atrial enlargement; $L A E$, left atrial enlargement; $R V I H$, right ventricular hypertrophy; $L V H$, left ventricular hypertrophy; NSSTWC, nonspecific ST-T wave changes.

Surface 12-lead ECGs (Table II). ECGs obtained at hospital discharge were available for review in 199 $(87 \%)$ survivors with TGA/IVS. The rhythm was sinus in 195 (98\%), 3 had an ectopic atrial rhythm, and 1 had atrial bigeminy. The mean heart rate was $141 \pm 16$ beats/min (range 100 to 205 beats $/ \mathrm{min}$ ). The mean PR interval was $0.11 \pm 0.02$ second (range 0.07 to 0.17 second), 5 patients had firstdegree heart block (PR interval $>160 \mathrm{msec}$ ), and one had Mobitz type II block. No patient with TGA/IVS had complete heart block. The mean QRS duration was $0.06 \pm 0.01$ second (range 0.04 to 0.13 second); 54 (27\%) patients had an RSR' pattern and $9(5 \%)$ had a complete right bundle branch block pattern.

ECGs obtained at hospital discharge were available for review in $149(93 \%)$ survivors with TGA/ VSD. The rhythm was sinus in 139 (93\%). In the remaining 10 , ectopic atrial rhythm was present in 2 $(1.3 \%)$, junctional rhythm in $2(1.3 \%)$, and a ventricular paced rhythm in $6(4 \%)$. Excluding patients with ventricular pacing, the mean heart rate was $131 \pm 20$ beats $/ \mathrm{min}$ (range 75 to 195 beats $/ \mathrm{min}$ ) and the mean PR interval was $0.12 \pm 0.02$ second (range 0.08 to 0.28 second). The mean QRS duration was
$0.09 \pm 0.02$ second (range 0.04 to 0.18 second), with a complete right bundle branch block in $66(44 \%)$, bifascicular block in $10(6.7 \%)$, and an RSR' pattern in $5(3.4 \%)$. First-degree heart block was seen in 2 patients $(1.3 \%)$.

Follow-up ECGs were reviewed in 147 patients with TGA/IVS. The mean length of follow-up was $2.0 \pm 2.0$ years (range 1 month to 8.7 years, median 12.8 months). Sinus rhythm was present in 143 of 147 (97\%) patients. Ectopic atrial rhythm was seen in 2 patients and junctional rhythm in 1 . The mean heart rate was $110 \pm 24$ beats/min (range 60 to 180 beats $/ \mathrm{min}$ ). The mean PR interval was $0.12 \pm 0.02$ second (range 0.08 to 0.21 second). First-degree heart block was seen in $3(2 \%)$. No second- or third-degree block was present. The mean QRS duration was $0.07 \pm 0.01$ second (range 0.04 to 0.12 second) with complete right bundle branch block in 5 patients $(3 \%)$ and an RSR $^{\prime}$ pattern in $45(31 \%)$.

Follow-up ECGs were reviewed in 147 patients with TGA/VSD. The mean length of follow-up was $1.3 \pm 1.7$ years (range 1 month to 7.8 years, median 8.5 months). The rhythm was sinus in $138(94 \%)$. An ectopic atrial rhythm was present in $3(2 \%)$ patients, a junctional rhythm in $1(0.6 \%)$, and 5 were paced 
Table III. Twenty-four-hour Holter monitor

\begin{tabular}{|c|c|c|c|c|c|c|c|c|}
\hline & \multicolumn{4}{|c|}{$T G A / I V S$} & \multicolumn{4}{|c|}{$T G A / V S D$} \\
\hline & \multicolumn{2}{|c|}{$\begin{array}{c}\text { Postop. } \\
(n=189)\end{array}$} & \multicolumn{2}{|c|}{$\begin{array}{l}\text { Follow-up } \\
(n=172)\end{array}$} & \multicolumn{2}{|c|}{$\begin{array}{c}\text { Postop. } \\
(n=136)\end{array}$} & \multicolumn{2}{|c|}{$\begin{array}{l}\text { Follow-up } \\
(n=46)\end{array}$} \\
\hline & No. & $\%$ & No. & $\%$ & No. & $\%$ & No. & $\%$ \\
\hline Sinus rhythm & 185 & 98 & 171 & 99 & 126 & 93 & 44 & 96 \\
\hline Occasional APB & 108 & 57 & 110 & 64 & 95 & 70 & 21 & 46 \\
\hline Frequent APB & 40 & 21 & 30 & 17 & 20 & 15 & 1 & 2 \\
\hline SVT (nonsustained) & 7 & 4 & 7 & 4 & 3 & 2 & 0 & \\
\hline SVT (sustained) & 16 & 8 & 5 & 3 & 2 & 1 & 0 & \\
\hline Occasional VPB & 97 & 51 & 71 & 42 & 78 & 57 & 13 & 28 \\
\hline Frequent VPB & 9 & 5 & 8 & 5 & 5 & 4 & 1 & 2 \\
\hline Multiform VPB & 0 & & 0 & & 0 & & 0 & \\
\hline Couplets & 18 & 10 & 19 & 11 & 4 & 3 & 0 & \\
\hline VT (nonsustained) & 2 & 1 & 2 & 1 & 1 & 0.5 & 0 & \\
\hline VT (sustained) & 4 & 2 & 1 & 0.5 & 1 & 0.5 & 0 & \\
\hline
\end{tabular}

$T G A$, Transposition of the great arteries; $I V S$, intact ventricular septum; $V S D$, ventricular septal defect; postop, obtained at hospital discharge; $A P B$, atrial premature beats; $S V T$, supraventricular tachycardia; $V P B$, ventricular premature beats; $V T$, ventricular tachycardia.

for complete heart block. First-degree block was seen in $4(3 \%)$ and Mobitz type II in $2(1 \%)$. Excluding paced patients, the mean heart rate was $118 \pm 29$ beats/min (range 55 to 190 beats/min) and the mean PR interval was $0.12 \pm 0.02$ second (range 0.08 to 0.24 second). The mean QRS duration was $0.09 \pm 0.02$ second (range 0.04 to 0.18 second) with complete right bundle branch block present in 75 $(51 \%)$, bifascicular block in $12(8.2 \%)$, and RSR' in $29(20 \%)$.

Other abnormal findings seen on the surface ECG (e.g., chamber enlargement and hypertrophy, ST segment abnormalities) are also presented in Table II.

Twenty-four-hour ambulatory ECG monitoring (Table III). Discharge Holter monitors were reviewed in 189 (82\%) of the hospital survivors with TGA/IVS. Predominant sinus rhythm was found in $185(98 \%)$ patients, and ectopic atrial rhythms were present in $4(2 \%)$. The lowest rate was $114 \pm 17.0$ beats/min (range 72 to 150 beats/min), and the upper rates were $175 \pm 18.2$ beats/min (range 137 to 270 beats/min). Occasional atrial ectopy was seen in $108(57 \%)$ patients and frequent atrial ectopy in 40 (21\%). Episodes of supraventricular tachycardia were seen in $23(12 \%)$ patients; $16(8 \%)$ patients had sustained and 7 nonsustained supraventricular tachycardia. One episode of atrial fibrillation occurred and no episodes of atrial flutter. Ventricular ectopy was present in $130(69 \%)$ patients. The ventricular ectopy was occasional in $97(51 \%)$ and frequent in $9(5 \%)$ patients. There were $18(10 \%)$ patients with couplets. Ventricular tachycardia was seen in $6(3 \%)$ patients, 2 having short runs and 4 having sustained ventricular tachycardia.

Discharge Holter monitors were reviewed in 136 $(85 \%)$ of the hospital survivors with TGA/VSD. The rhythm was sinus in 126 (93\%) with ectopic atrial rhythm present in $2(1 \%)$ and accelerated junctional rhythm in $3(2 \%) ; 5$ were paced for complete heart block. The lowest rates were $101 \pm 17.6$ beats $/ \mathrm{min}$ (range 52 to 145 beats $/ \mathrm{min}$ ), and upper rates were $167 \pm 25.9$ beats $/ \mathrm{min}$ (range 109 to 264 beats $/ \mathrm{min}$ ). Occasional atrial ectopy was seen in $95(70 \%)$ patients and frequent atrial ectopy in $20(15 \%)$. Episodes of supraventricular tachycardia were noted in $5(4 \%)$ patients; of these 3 had nonsustained and 2 had sustained tachycardia. One episode of atrial flutter occurred. Ventricular ectopy was present in $89(65 \%)$ patients, occasional in $78(57 \%)$ and frequent in $5(4 \%)$. Couplets were noted in $4(3 \%)$ patients. Two (1\%) had ventricular tachycardia-1 being sustained ( 35 seconds at 150 beats $/ \mathrm{min}$ ) and the other a short 15-beat salvo at 170 beats/min.

Follow-up Holter monitor studies were performed in 172 hospital survivors with TGA/IVS, at a mean of $2.1 \pm 1.6$ years (range 1 month to 8.6 years, median 1.8 years) after the arterial switch operation. Sinus rhythm was present in all but 1 patient who had an ectopic atrial rhythm. The average low rate was $102 \pm 26$ beats/min ( 45 to 150 beats/min), and the upper rate was $174 \pm 21$ beats/min (100 to 225 beats/min). Occasional ectopic beats were seen in $110(64 \%)$ patients and frequent atrial ectopic beats in $30(17 \%)$. Episodes of supraventricular tachycardia were seen in $12(7 \%)$ patients. Of these, 7 
Volume 109, Number 2

episodes were nonsustained and 5 were sustained. No atrial flutter or fibrillation was noted. Ventricular ectopy was present in $101(59 \%)$ patients. Occasional ectopy was noted in $71(41 \%)$ and frequent in $8(5 \%)$. Couplets were noted in $19(11 \%)$ patients. Episodes of ventricular tachycardia were seen in 3 ( $2 \%$ ) patients. Of these, 1 episode was sustained (45 seconds at 160 beats $/ \mathrm{min}$ ) and 2 were short runs ( 8 beats at 145 beats $/ \mathrm{min}$ and 12 beats at 130 beats $/ \mathrm{min}$ ).

Follow-up Holter monitor studies were performed in 46 hospital survivors with TGA/VSD, at a mean of $2.4 \pm 1.7$ years (range 1 month to 7.5 years, median 1.8 years) after the arterial switch operation. The rhythm was sinus in all but 2 , which were paced. The average low rate was $73 \pm 21$ beats/min (range 44 to 129 beats $/ \mathrm{min}$ ), and the upper rate was $173 \pm$ 22 beats/min (range 116 to 219 beats/min). Occasional atrial ectopy was present in $21(46 \%)$ patients and frequent atrial ectopy in $1(2 \%)$. There were no episodes of supraventricular tachycardia. Ventricular ectopy was present in $14(30 \%)$, being occasional in $13(28 \%)$ and frequent in $1(2 \%)$. No episodes of ventricular tachycardia occurred.

Intracardiac electrophysiology. An intracardiac electrophysiologic study was performed during cardiac catheterization in 110 hospital survivors with TGA/IVS, at a mean of $12 \pm 8.1$ months (range 2 months to 5.9 years, median 11 months) after the arterial switch operation. The corrected sinus node recovery time ranged from 35 to $310 \mathrm{msec}$. Three (3\%) patients had values greater than $275 \mathrm{msec}$, the upper limit of normal. The $\mathrm{AH}$ intervals were 30 to $140 \mathrm{msec}$, with $12(11 \%)$ patients having values between 90 and $100 \mathrm{msec}$ and $5(4.5 \%)$ patients with values greater than $100 \mathrm{msec}$ (the upper limit of normal). The HV intervals ranged from 15 to 80 msec. Four (3.6\%) patients had values greater than 50 (the upper limit of normal). The right ventricular apex activation times were 5 to $40 \mathrm{msec}$, all within the normal (15 to $40 \mathrm{msec}$ ) range.

An intracardiac electrophysiologic study was performed during cardiac catheterization in 48 hospital survivors with TGA/VSD, at a mean of $11 \pm 4$ months (range 2 months to 1.8 years, median 10 months) after the arterial switch operation. The corrected sinus node recovery time ranged from 50 to $500 \mathrm{msec}$ with $6(12.5 \%)$ patients have values greater than $275 \mathrm{msec}$. The AH intervals were 50 to $110 \mathrm{msec}$ with $5(10 \%)$ being between 90 and 100 and 2 (4.2\%) greater than 100 msec. All HV intervals were in the normal range. The right ventricular apex activation times were 10 to $80 \mathrm{msec}$, with $8(17 \%)$ patients having values greater than $40 \mathrm{msec}$.

\section{Discussion}

Since 1983, the arterial switch operation has been the procedure of choice at Children's Hospital, Boston, for surgical management of patients with TGA/IVS, TGA/VSD, and transposition-like forms of double-outlet right ventricle. This report reviews the early and midterm (up to 8.6 years) rhythm status in 364 survivors of the arterial switch operation. Both noninvasive and invasive techniques were used. The results are similar to those previously reported, ${ }^{10,11,16-19}$ in that there appears to be a very low incidence of significant rhythm disturbances after the arterial switch operation.

The majority of patients in this study had preserved sinus node function, as observed by the fact that 281 of 294 (96\%) with follow-up ECGs had normal sinus rhythm at a follow-up ranging from 1 month to 8.5 years. This observation was also supported by follow-up 24-hour ambulatory monitoring, during which 214 of 217 (99\%) had predominant sinus rhythm at follow-ups ranging from 1 month to 8.6 years. The results of invasive intracardiac electrophysiologic studies also demonstrated normal corrected sinus node recovery times in 153 of 158 (97\%) patients at a mean follow-up of approximately 1 year, in agreement with a previous report by Vetter and Tanner. ${ }^{17}$

These results contrast sharply with data reported after atrial correction where, in one report by Flinn, Wolff, and Campbell, ${ }^{20}$ only $74 \%$ of patients were in stable sinus rhythm at 1 year's follow-up and only $35 \%$ at 10 years. Although studies by Turley and Ebert $^{21}$ and de Begona and associates ${ }^{22}$ suggested a lower incidence of arrhythmias in patients who underwent an early atrial level repair compared with those undergoing repair in later life, most reports suggest an incidence of rhythm disturbances in patients undergoing an atrial level repair of TGA ranging from $30 \%$ to $100 \% .^{3,5-7,23}$ Suggested mechanisms for atrial conduction abnormalities after atrial level correction are (1) damage to the sinus node or its blood supply, ${ }^{54}$ (2) interruption of intraatrial conduction pathways, ${ }^{25}$ and (3) damage to the atrioventricular node or its blood supply. ${ }^{26}$ Previous attempts have been made to protect these structures with surgical modifications of the Senning and Mustard procedures, but these have met with limited success. ${ }^{26-28}$ Also, despite some early optimism that the various modifications of the Senning 
procedure might decrease the incidence of atrial ectopy, ${ }^{29,} 30$ there appears to be little difference in the incidence of late sinus node dysfunction and atrial arrhythmias in patients undergoing either a Mustard or a Senning procedure. ${ }^{31,32}$

The decreased incidence of atrial arrhythmias after the arterial switch operation is likely due to the limited atrial operation; cannulation of the right atrial appendage, atriotomy, and suture (or patch) closure of the atrial defect (either congenital or iatrogenic) are the only intraatrial manipulations during the arterial switch operation. Also, because patients having a primary arterial switch operation must undergo repair in the neonatal period, the likelihood of a prior surgical atrial septectomy is lessened. In 1983, Arensman and associates ${ }^{19}$ proposed that the lower incidence of postoperative arrhythmias in patients having an arterial switch operation may be due to changes in the septectomy (a modified Blalock-Hanlon) and the fact it could be closed with a single suture. This allowed the atrial septum to be left basically intact without damage to the sinus node or its blood supply, specialized intraatrial conduction pathways, or the atrioventricular node. It was also suggested that the intraatrial suture lines lead to scarring that produce areas of slow conduction that in turn predispose to reentry tachycardia.

In our study group, atrioventricular conduction was also well maintained as demonstrated on follow-up ECG, with only 7 (2\%) patients with firstdegree block, 2 with second-degree block, and 5 with complete atrioventricular block. All patients with second- and third-degree block had an associated VSD closed at the time of the arterial switch operation. The $\mathrm{AH}$ and $\mathrm{HV}$ intervals were also normal in the majority of cases.

Complete right bundle branch block was a common finding in patients with TGA/VSD after surgical correction, although bifascicular block and complete heart block were rare. In patients with TGA/ VSD having invasive electrophysiologic study after operation, the complete right bundle branch block was "central" in all but 1 patient, suggesting that the cause was the VSD closure. In contrast, 5 patients with TGA/IVS also had complete right bundle branch block, which persisted during the follow-up period. In 4 of these patients, a small branch of the left coronary artery supplying the infundibulum was sacrificed to allow adequate posterior mobilization of the left coronary artery. This resulted in a small area of infarction in the infundibulum and, most likely, a "peripheral" complete right bundle branch block (invasive right ventricular apex activation times were not measured in these 4 patients). The remaining patient with TGA/IVS and a complete right bundle branch block had division of right ventricular muscle bundles 3 weeks after the arterial switch operation; at follow-up catheterization, right ventricular apex activation time was not measured.

Both atrial and ventricular ectopy are somewhat more prevalent in our patient population than previously reported after the arterial switch operation; Martin, Radley-Smith, and Yacoub ${ }^{10}$ found only $23 \%$ of 40 patients with TGA/IVS had supraventricular premature beats, at a mean follow-up of 3.1 years after an arterial switch operation. In this study 152 of $172(81 \%)$ patients had atrial ectopy at a mean follow-up of 2.1 years, the majority $(64 \%)$ of whom had only occasional ectopy. In addition, $70 \%$ of patients (both TGA/IVS and TGA/VSD) had ventricular ectopy on their discharge Holter monitor studies. These values fell to $57 \%$ and $30 \%$, respectively, at the time of follow-up studies. In a previous report, Deanfield, Camm, and Macartney ${ }^{33}$ found $47 \%$ of patients had ventricular ectopy at discharge and $24 \%$ at follow-up.

In our patient population, arrhythmias were much more frequent immediately after the operation than at discharge or during follow-up. These included 25 episodes of supraventricular tachycardia, 6 of junctional ectopic tachycardia, and 9 episodes of ventricular tachycardia. In our study, the number of patients with supraventricular tachycardia at follow-up had fallen to $12(5 \%)$ with no atrial flutter or fibrillation noted. Three patients had ventricular tachycardia on follow-up Holter monitor studies with the longest episode being 15 beats at 150 beats/min.

The incidence and severity of ventricular ectopy and nonsustained ventricular tachycardia seen on the 24-hour ambulatory ECG at discharge was somewhat surprising. Although late follow-up studies seem to show a decreasing incidence of ventricular ectopy/tachycardia with time, serial studies were not obtained in a large number of patients. This variability in follow-up compliance thus makes it difficult to accurately quantify the long-term significance of this finding. Also, there is no adequate "control" population with which to compare our findings. Although isolated ventricular ectopy and ventricular tachycardia are certainly more prevalent than that in normal infants, other neonates and infants who have had other types of cardiac surgery 
Volume 109, Number 2

(with myocardial ischemia and cardioplegia) seem to be a more analogous control group. At present, these studies are not available.

Potential causes of postoperative ventricular ectopy include (1) ischemia after coronary mobilization and transfer, (2) VSD closure (when present), and (3) electrolyte imbalance from diuretic therapy. Although ventricular ectopy does not seem to be a clinical problem over the short term, the incidence and severity probably decrease with time (in contrast to atrial level repairs). ${ }^{1-10,20,22,24-28,33}$ Moreover, a recent study showed no exercise-induced ectopy (atrial or ventricular) in 23 patients after an arterial switch operation. ${ }^{34}$ Regardless of the cause, ventricular ectopy may be a marker for ventricular dysfunction or coronary insufficiency and requires serial follow-up.

In summary, our results confirm the theoretical advantages of anatomic correction by the arterial switch operation over atrial level correction of TGA with respect to better preservation of the conduction system and the elimination of significant sinus node disease.

We thank Dr. Aldo R. Castaneda, Dr. Richard A. Jonas, Dr. Frank L. Hanley, and Dr. William I. Norwood, who operated on some of the patients in this series. We also thank Matthew Martin and Tannis Bolton for help with data acquisition and manuscript preparation.

\section{REFERENCES}

1. Mustard WT. Successful two-stage correction of transposition of the great vessels. Surgery 1964;55: 469-72.

2. Senning A. Surgical correction of transposition of the great vessels. Surgery 1959;45:966-80.

3. Beerman LB, Neches WH, Fricker FJ, et al. Arrhythmias in transposition of the great arteries after the Mustard operation. Am J Cardiol 1983;51:1530-5.

4. Saalouke MG, Rios J, Perry LW, Shapiro SR, Scott LP. Electrophysiologic studies after Mustard's operation for d-transposition of the great vessels. Am J Cardiol 1978;4:1104-9.

5. El-Said G, Rosenberg HS, Mullins CE, Hallman GL, Cooley DA, McNamara DG. Dysrhythmias after Mustard's operation for transposition of the great arteries. Am J Cardiol 1972;30:526-32.

6. Gillette PC, El-Said GM, Sivaravan N, Mullins CE, Williams RL, McNamara DG. Electrophysiological abnormalities after Mustard's operation for transposition of the great arteries. Br Heart J 1974;36: 186-91.

7. Gillette PC, Kugler JD, Garson A, Gutgesell HP, Duff DF, McNamara DG. Mechanisms of cardiac arrhyth- mias after the Mustard operation for transposition of the great arteries. Am J Cardiol 1980;45:1225-30.

8. Martin TC, Smith L, Hernandez AN, Weldon CS. Dysrhythmias following the Senning operation for dextro-transposition of the great arteries. J THORAC Cardiovasc Surg 1983;85:928-32.

9. Byrum CJ, Bove EL, Sondheimer HM, Kavey RW, Blackman MS. Hemodynamic and electrophysiologic results of the Senning procedure for transposition of the great arteries. Am J Cardiol 1986;58:138-42.

10. Martin RP, Radley-Smith R, Yacoub MH. Arrhythmias before and after anatomic correction of transposition of the great arteries. J Am Coll Cardiol 1987; 10:200-4.

11. Wernovsky G, Hougen TJ, Walsh EP, et al. Midterm results after the arterial switch operation for transposition of the great arteries with intact ventricular septum: clinical, hemodynamic, echocardiographic and electrophysiologic data. Circulation 1988;77: 1333-44.

12. Garson A Jr. The normal electrocardiogram. In: The electrocardiogram in infants and children: a systematic approach. 1st ed. Philadelphia: Lea \& Febiger, 1983:61-82.

13. Walsh EP, Keane JF. Electrophysiologic studies in congenital heart disease and related studies. In: Lock JE, Keane JF, Fellows KE, eds. Diagnostic and interventional catheterization in congenital heart disease. 1st ed. Boston: Matinus Nijhoff, 1987:161-81.

14. Di Donato RM, Wernovsky G, Walsh EP, et al. Results of the arterial switch operation for transposition of the great arteries with ventricular septal defect: surgical considerations and midterm follow-up data. Circulation 1989;80:1689-705.

15. Wernovsky G, Mayer JE Jr, Jonas RA, et al. Factors influencing early and late outcome of the arterial switch operation for transposition of the great arteries. J THORAC Cardiovasc Surg 1995;109:289-302.

16. Menahem S, Ranjit MS, Stewart C, Brawn WJ, Wilkinson JL. Cardiac conduction abnormalities and rhythm changes after neonatal anatomical correction of transposition of the great arteries. $\mathrm{Br}$ Heart J 1992;67:246-9.

17. Vetter VL, Tanner CS. Electrophysiologic consequences of the arterial switch repair of d-transposition of the great arteries. J Am Coll Cardiol 1988;12:22937.

18. Lange PE, Sievers H, Wessel A, et al. Cardiac rhythm and conduction after two-stage anatomic correction of simple transposition of the great arteries. Thorac Cardiovasc Surg 1986;34:22-4.

19. Arensman FW, Bostock J, Radley-Smith R, Yacoub MH. Cardiac rhythm and conduction before and after anatomic correction of transposition of the great arteries. Am J Cardiol 1983;52:836-9.

20. Flinn CJ, Wolff GS, Campbell RM. Natural history of 
supraventricular rhythms in 182 children following the Mustard operation: a collaborative multicenter study. J Am Coll Cardiol 1983;1:613.

21. Turley K, Ebert PA. Total correction of transposition of the great arteries: conduction disturbances in infants younger than three months of age. $J$ THORAC Cardiovasc Surg 1978;76:312-20.

22. de Begona AJ, Kawauchi M, Fullerton D, Razzouk AJ, Gundry SR, Bailey LL. The Mustard procedure for correction of simple transposition of the great arteries before 1 month of age. J THORAC CARDIOvasC SURG 1992;104:1218-24.

23. Trusler GA, Williams WG, Izukawa T, Olley PM. Current results with the Mustard operation in isolated transposition of the great arteries. J THORAC CARDIOVASC SURG 1980;80:381-9.

24. Gillette PC, El-Said GM, Mullins CM, Williams RL, McNamara DG. Electrophysiologic abnormalities after Mustard's operation for transposition of the great arteries. Br Heart J 1974;36:186-91.

25. Isaacson R, Titus JL, Merideth J, Feldt RH, McGoon DW. Apparent interruption of atrial conduction pathways after surgical repair of transposition of great arteries. Am J Cardiol 1972;30:533-5.

26. Ullal RR, Anderson RH, Lincoln C. Mustard's operation modified to avoid dysrhythmias and pulmonary and systemic venous obstruction. J THORAC CARDIOVASC SuRg 1979;78:431-9.

27. Egloff LP, Freed MD, Dick M, Norwood WI, Castañeda AR. Early and late results with the Mustard operation in infancy. Ann Thorac Surg 1978;26:47484.
28. El-Said GM, Gillette PC, Cooley DA, Mullins CE, McNamara DG. Protection of the sinus node in Mustard's operation. Circulation 1972;53:788-91.

29. Marquez-Montes J, O'Connor F, Burgos R, Hernandez C, Montero C, Castillo-Olivares JL. Comparative electrophysiological evaluation of atrial activation and sinoatrial node function following Senning and Mustard procedures: an experimental study. Ann Thorac Surg 1983;36:692-9.

30. Byrum CJ, Bove EL, Sondheimer HM, Kavey RW, Blackman MS. Sinus node shift after the Senning procedure compared with the Mustard procedure for transposition of the great arteries. Am J Cardiol 1987;60:346-50.

31. Stark J. Evaluation of inflow-type repairs for transposition of the great arteries. Pediatr Cardiol 1980;4: I159-64.

32. Anderson RH. Description of the origins and epicardial course of the coronary arteries in complete transposition. Cardiol Young 1991;1:11-2.

33. Deanfield JE, Camm J, Macartney F. Arrhythmia and late mortality after Mustard and Senning operation for transposition of the great arteries: an eight-year prospective study. J Thorac Cardiovasc Surg 1988; 96:569-76.

34. Weindling SN, Wernovsky G, Colan SD, et al. Myocardial perfusion, function and exercise tolerance after the arterial switch operation. J Am Coll Cardiol 1994;23:424-33.

\section{Availability of JournaL back issues}

As a service to our subscribers, copies of back issues of The Journal of THORACIC AND CARDiovascular SuRGERY for the preceding 5 years are maintained and are available for purchase from the publisher, Mosby-Year Book, Inc., at a cost of $\$ 12.00$ per issue. The following quantity discounts are available: $25 \%$ off on quantities of 12 to 23 , and one third off on quantities of 24 or more. Please write to Mosby-Year Book, Inc., Subscription Services, 11830 Westline Industrial Drive, St. Louis MO 63146-3318, or call (800)453-4351 or (314)453-4351 for information on availability of particular issues. If unavailable from the publisher, photocopies of complete issues are available from University Microfilms International, 300 N. Zeeb Rd., Ann Arbor, MI 48106, (313) $761-4700$. 